\title{
Alcohol use, opioid overdose and socioeconomic status in Canada: A threat to life expectancy?
}

\author{
Charlotte Probst PhD, Jürgen Rehm PhD
}

Cite as: CMAJ 2018 November 5;190:E1294-5. doi: 10.1503/cmaj.180806

\footnotetext{
n
} n 2015, Case and Deaton reported that life expectancy for middle-aged, white, non-Hispanic people in the United States had declined in the first decade of the 21 st century. ${ }^{1}$ For the better half of a century before that, life expectancy at birth had increased in both Canada and the US. Life expectancy depends on the age structure of the population and the age-specific mortality rates in a given country, with deaths that occur early in life having a higher impact. More recent work has shown that life expectancy at birth has been stagnating or slowly declining for the whole US population, from 78.5 years in 2010 to 78.8 and 78.7 years in 2014 and 2016, respectively. ${ }^{2,3}$ In Canada, life expectancy is higher than in the US and has continued to increase (2010: 81.2; 2014: 82.0; 2016: 82.3), albeit at a slower pace than before. ${ }^{3}$ Despite demographic differences between the two countries, there are important similarities with regard to the income level and economic developments, as well as exposure levels to major risk factors. Is Canada at risk of a reversal of life expectancy? We examine core drivers of the development in life expectancy in the US to answer this question.

Substance use and socioeconomic factors have greatly affected the current trends in life expectancy. ${ }^{2,4}$ The largest increases in mortality rates in the US have resulted from the so-called "deaths of despair" (i.e., poisoning, suicide and alcoholic liver disease ${ }^{4}$ ), as well as from other unintentional injuries, other liver diseases, pneumonia and diabetes mellitus. ${ }^{2}$ Among younger American adults (15-49 yr), alcohol and drug use are by far the most important risk factors for mortality. ${ }^{5}$ Since 1990 , the proportion of deaths attributable to alcohol and drug use increased from $20 \%$ to nearly $30 \%$ in $2016 . .^{5}$ Mortality rates, particularly for "deaths of despair," all of which are causally linked to substance use, increased disproportionately in lower socioeconomic strata. ${ }^{2,4}$ Furthermore, despite unchanging or slowly increasing overall per capita consumption in the US, heavy drinking and alcohol use disorders increased markedly in lower socioeconomic strata. ${ }^{6}$

Similarly, in Canada, alcohol and drug use were identified as the most important risk factors among younger adults, accounting for less than $20 \%$ in 1990 and $25 \%$ of the total deaths in 2016, respectively. "Deaths of despair" are also prevalent in Canada. Deaths from opioid overdoses have risen to record levels for each of the past few years; current estimates suggest close to or more than 4000 such deaths for $2017 .{ }^{7}$ Deaths and hospital admissions

\section{KEY POINTS}

- Growth in life expectancy in the United States has stagnated and even decreased slightly in recent years, driven largely by deaths attributed to alcohol and drug use or to suicide in lower socioeconomic strata.

- In Canada, the rates of these "deaths of despair" have also increased, particularly for opioid overdoses and alcoholic liver cirrhosis.

- However, mortality rates in Canada for key causes of death are markedly lower than in the US, and the income gap between high and low socioeconomic strata is narrower.

- As such, it is important for Canada to avoid further inequalities in income, to reduce rates of opioid prescribing and to strengthen alcohol control policies.

attributable to alcohol have also increased markedly, ${ }^{8}$ paralleling the increases in the US. However, Canada's mortality rates are still substantially lower for both opioid-related deaths and for the most important alcohol-attributable death, alcoholic liver cirrhosis. Furthermore, while suicide rates have decreased in Canada since 2000, there has been a steady increase in suicide deaths in the US. ${ }^{5}$

As in the US, marked socioeconomic differences exist for "deaths of despair" in Canada. A large longitudinal study found 3.6- to 5.0-fold mortality risks for causes of death fully attributable to drug or alcohol use among men and women in the lowest, compared with the highest, income quintiles. ${ }^{9}$ This compares with a 1.5- to 1.7-fold mortality risk observed for all-cause mortality, indicating synergistic effects between socioeconomic status and substance use. , $^{9}$

There are a few important differences between Canada and the US: economic inequalities in Canada are less pronounced and the proportion of people considered to be living below the poverty line is smaller, although income inequality has increased in recent years. ${ }^{3}$ In addition, demographic differences exist. Canada's population is older, with lower birth and growth rates, different racial distributions and a higher migration rate. However, none of these characteristics can fully explain the differing trends in life expectancy between the two countries.

What is maintaining the differences between the US and Canada in overall mortality rates and cause-specific mortality? First, per 
capita use of prescription opioids is highly associated with levels of nonmedical opioid use, use disorders and subsequent deaths. ${ }^{11}$ Although the US and Canada have the highest use of prescription opioids globally, per capita opioid use in the US is about $50 \%$ higher than in Canada. ${ }^{12}$ Second, a recent report by the Canadian Institutes for Health Information found heavy alcohol use was more prevalent in higher-income groups in Canada, ${ }^{8}$ with no substantial increases in heavy drinking or in alcohol use disorders in lower socioeconomic strata. Thus, although there may be similar interaction effects between socioeconomic status and heavy drinking in Canada and the US, there is a lower prevalence of heavy drinking among individuals with lower socioeconomic status in Canada and hence lower levels of alcohol-attributable mortality. ${ }^{2,9,10}$ This may be because alcohol is less affordable in Canada and there is less marked poverty and income inequality in Canada than the US.

Given this evidence, Canada should make an effort to maintain or decrease current opioid prescription rates, and to maintain high taxation and restricted availability of alcohol in line with World Health Organization recommendations, in order to avoid following the US into a state of declining life expectancy. Furthermore, as mortality rates are highest among those with the lowest socioeconomic status, we must work to prevent increases in socioeconomic inequalities in Canada.

\section{References}

1. Case A, Deaton A. Rising morbidity and mortality in midlife among white nonHispanic Americans in the 21st century. Proc Natl Acad Sci U S A 2015;112:15078-83.

2. Rehm J, Probst C. Decreases of life expectancy despite decreases in noncommunicable disease mortality: The role of substance use and socioeconomic status. Eur Addict Res 2018;24:53-9.

3. World development indicators [data bank]. Washington (DC): The World Bank Group; 2018. Available: http://databank.worldbank.org/data/reports. aspx?source=world-development-indicators (accessed 2018 Sept. 17).

4. Case A, Deaton A. Mortality and morbidity in the 21st century. Brookings Pap Econ Act 2017;2017:397-476

5. GBD Compare. Seattle (WA): Institute for Health Metrics and Evaluation; 2018. Available: http://vizhub.healthdata.org/gbd-compare/ (accessed 2018 Sept. 25).
6. Grant BF, Chou SP, Saha TD, et al. Prevalence of 12-month alcohol use, high-risk drinking, and DSM-IV alcohol use disorder in the United States, 2001-2002 to 2012-2013: results from the National Epidemiologic Survey on Alcohol and Related Conditions. JAMA Psychiatry 2017;74:911-23.

7. Special Advisory Committee on the Epidemic of Opioid Overdoses. National report: Apparent opioid-related deaths in Canada (January 2016 to September 2017) [web-based report]. Ottawa: Public Health Agency of Canada; March 2018 (updated 2018 Aug. 24). Available: www.canada.ca/en/public-health/ services/publications/healthy-living/national-report-apparent-opioid-related -deaths-released-march-2018.html (accessed 2018 June 6).

8. Alcohol harm in Canada: examining hospitalizations entirely caused by alcohol and strategies to reduce alcohol harm. Ottawa: Canadian Institute for Health Information; 2017. Available: www.cihi.ca/sites/default/files/document/report -alcohol-hospitalizations-en-web.pdf (accessed 2018 June 4).

9. Tjepkema M, Wilkins R, Long A. Cause-specific mortality by income adequacy in Canada: a 16-year follow-up study. Health Rep 2013;24:14-22.

10. Katikireddi SV, Whitley E, Lewsey J, et al. Socioeconomic status as an effect modifier of alcohol consumption and harm: analysis of linked cohort data. Lancet Public Health 2017;2:e267-76.

11. Imtiaz S, Shield KD, Fischer B, et al. Harms of prescription opioid use in the United States. Subst Abuse Treat Prev Policy 2014;9:43.

12. International Narcotics Control Board (INCB). Narcotic drugs: Estimated world requirements for 2018; statistics for 2016 [technical report]. New York: United Nations; 2017. Available: www.incb.org/documents/Narcotic-Drugs/Technical-Publications /2017/3_Introduction_E.pdf (accessed 2018 Nov. 6).

\section{Competing interests: None declared.}

This article has been peer reviewed.

Affiliations: Institute for Mental Health Policy Research (Probst, Rehm), Centre for Addiction and Mental Health (CAMH); Department of Psychiatry (Rehm), University of Toronto, Toronto, Ont.

Contributors: Jürgen Rehm and Charlotte Probst conceptualized the work; Jürgen Rehm wrote the first draft and both authors critically revised multiple versions of the article before first submission. Charlotte Probst took major responsibility for the revision to which both authors made significant contributions. Both authors gave final approval of the version to be published and agreed to be accountable for all aspects of the work.

Correspondence to: Jürgen Rehm, jtrehm@gmail.com 